\title{
Baculoviral inhibitor of apoptosis family of proteins repeat-containing 5 gene methylation status in peripheral blood mononuclear cells and plasma survivin levels in patients with Behçet's disease
}

\author{
Yasamin Pahlavan ${ }^{1}$ D, Alireza Khabbazi² ${ }^{\text {ID }}$ \\ ${ }^{1}$ Department of Molecular Medicine, Faculty of Advanced Medical Sciences, Tabriz, Iran \\ ${ }^{2}$ Department of Internal Medicine, Connective Tissue Diseases Research Center, Tabriz, Iran
}

\begin{abstract}
Objectives: This study aims to evaluate the baculoviral inhibitor of apoptosis repeat-containing 5 (BIRC5) gene methylation in the peripheral blood mononuclear cells (PBMCs) in patients with Behçet's disease (BD) compared to healthy controls and the association of survivin with BD activity.

Patients and methods: A cross-sectional study was conducted on 43 BD patients (22 males, 21 females; mean age $36.6 \pm 10.1$ years; range, 18 to 66 years) and 44 age- and sex-matched healthy controls ( 23 males, 21 females; mean age $35.4 \pm 7.5$ years; range, 18 to 61 years) between August 2019 and December 2019. Sample size was calculated guided by taking into account the difference of 1.5 units between the mean expression of BIRC5 gene in the BD and control groups, as well as considering $\mathrm{a}=0.5$ and power $=80 \%$. We assessed the methylation status of the BIRC5 gene in PBMCs of BD and control groups by methylation-specific polymerase chain reaction (MS-PCR). Plasma levels of survivin were measured by enzymelinked immunosorbent assay.

Results: Oral aphthous ulcer, genital ulcer, and skin lesions were the most common clinical manifestations in BD group. MS-PCR showed that the deoxyribonucleic acid samples of BD and control groups were not different in methylated and unmethylated areas and alleles were heterozygote. No significant difference was observed in the plasma levels of survivin in BD $(98.86 \pm 25.5 \mathrm{pg} / \mathrm{mL})$ and control $(118.16 \pm 37.4 \mathrm{pg} / \mathrm{mL}) \mathrm{groups}$. There was no significant correlation between survivin plasma levels and BD activity.

Conclusion: Our study did not show any evidence of association between the alteration in the BIRC5 gene methylation, survivin production, and apoptosis dysregulation in BD.

Keywords: Apoptosis, Behçet's disease, methylation, survivin.
\end{abstract}

Behçet's disease (BD) is an autoimmune/ autoinflammatory disorder with a broad range of clinical manifestations including recurrent oral aphthous ulcers, genital ulcers, uveitis, erythema nodosum, pseudofolliculitis, and arthritis. Although the etiology of $\mathrm{BD}$ is unknown, immune system dysregulation triggered by environmental factors, including microbial agents, vitamin $\mathrm{D}$ deficiency, and smoking play an important role. ${ }^{1-3}$ Many studies revealed the role of genetic background in the immune system dysregulation and autoimmunity development in BD. ${ }^{4-6}$ In $\mathrm{BD}$, innate and acquired immune system dysfunction lead to presentation of microbial and

Received: April 19, 2020 Accepted: June 21, 2020 Published online: January 14, 2021

Correspondence: Alireza Khabbazi, MD. Department of Internal Medicine, Connective Tissue Diseases Research Center, 5167747899 Tabriz, Iran. Tel: 00984133332704 e-mail:dr.khabazi@gmail.com

\section{Citation:}

Pahlavan Y, Khabbazi A. Baculoviral inhibitor of apoptosis family of proteins repeat-containing 5 gene methylation status in peripheral blood mononuclear cells and plasma survivin levels in patients with Behçet's disease. Arch Rheumatol 2021;36(2):185-191. 
self antigens to the T-cells and hyperactivation of them. ${ }^{7,8}$ Regulatory mechanism can control immune response and prevent autoimmunity. Apoptosis is one of the mechanisms that by deleting hyperreactive $\mathrm{T}$-cells control immune response and plays a key role in the pathogenesis of many autoimmune diseases. ${ }^{7,8}$ Many studies introduced the role of apoptosis dysregualtion in the pathogenesis of $\mathrm{BD} .^{9-14}$

Survivin belong to a group of proteins named inhibitor of apoptosis proteins (IAPs), which stop apoptosis by inhibiting function of caspases 3 and 9.7 Baculoviral IAPs repeat-containing 5 (BIRC5) gene has the function of encoding survivin. ${ }^{7}$ Survivin expression is dysregulated in various autoimmune diseases including systemic lupus erythematous, systemic sclerosis, and rheumatoid arthritis (RA). ${ }^{7,15,16}$ Higher survivin levels in the sera of RA patients in comparison to healthy controls suggested that survivin could be considered as a possible biomarker for the diagnosis and monitoring of RA disease activity. ${ }^{17,18}$ A preliminary study showed high expressions of the BIRC 5 gene in the peripheral blood mononuclear cells (PBMCs) of patients with $\mathrm{BD}$ and higher plasma levels of survivin in BD patients compared with controls. ${ }^{19}$ However, differences in the plasma levels of survivin did not reach significant levels. ${ }^{19} \mathrm{We}$ hypothesized that a type II error occurred and by increasing the sample size, we could prove an increased production of survivin. In addition, we hypothesized that epigenetic mechanisms may be responsible for the higher expression of the BIRC5 gene and increased production of survivin in $\mathrm{BD}$ patients. The epigenetic mechanism has been shown to affect the genes expression by altering the physical structure of deoxyribonucleic acid (DNA). ${ }^{20}$ DNA methylation is an epigenetic mechanism that affects the expression of specific genes by adding a methyl group to the part of DNA that occurs most frequently at the 5' end of guanine in $\mathrm{CpG}$ (cytosine-phosphate-guanine) dinucleotide. ${ }^{20}$ Recent studies showed the role of DNA methylation in the pathogenesis of BD. ${ }^{21-24}$ Therefore, in this study, we aimed to evaluate the BIRC5 gene methylation in the PBMCs and plasma levels of survivin in patients with $\mathrm{BD}$ compared to healthy controls and the association of survivin with BD activity.

\section{PATIENTS AND METHODS}

This cross-sectional study was conducted at Connective Tissue Diseases Research Center of Tabriz University of Medical Sciences between August 2019 and December 2019. Forty-four patients with $\mathrm{BD}$ and 44 age- and sex-matched healthy controls were enrolled in this study. One-to-one matching was performed. However, one of the $\mathrm{BD}$ patients was excluded due to a technical problem with DNA isolation. Thus, a total of 43 BD patients (22 males, 21 females; mean age $36.6 \pm 10.1$ years; range, 18 to 66 years) and 44 age- and sex-matched healthy controls (23 males, 21 females; mean age $35.4 \pm 7.5$ years; range, 18 to 61 years) were included. Sample size was calculated guided by taking into account the difference of 1.5 units between the mean expression of BIRC5 gene in the BD and control groups, as well as considering $\alpha=0.5$ and power $=80 \%$. The controls were selected from the students and staff of the School of Modern Medical Sciences who were invited to study by advertisements. Three controls were selected for both patients. Inclusion criteria were: (i) fulfillment of the International Criteria of Behçet's Disease; ${ }^{25}$ (ii) age over 16 years, and (iii) having active disease. Exclusion criteria for $\mathrm{BD}$ and control groups were having underlying diseases including malignancy, human immunodeficiency virus infection, other inflammatory and autoimmune disorders, liver disease, diabetes mellitus, kidney disease, and ever smoking. We measured BD activity using Behçet's Disease Current Activity Form (BDCAF), Iranian Behçet's Disease Dynamic Activity Measure (IBDDAM), and Total Inflammatory Activity Index (TIAI). ${ }^{26,27}$ Patients with $\mathrm{BDCAF} \geq 1$ were classified as active BD. ${ }^{28}$ The study protocol was approved in June 2019 by the Tabriz University of Medical Sciences Ethics Committee (ethical code: IR TBZMED. REC.1397.190). A written informed consent was obtained from each participant. The study was conducted in accordance with the principles of the Declaration of Helsinki.

Five milliliter of blood was drawn from the cubital vein of all the participants after 12 hours of overnight fasting. The blood samples were transferred directly to the sodium citrate tubes. PBMCs were isolated immediately with 


\begin{tabular}{|c|c|c|}
\hline Gene & Sequence & Product size \\
\hline \multicolumn{3}{|l|}{ GAPDH } \\
\hline Forward & AATGGGCAGCCGTTAGGAAA & \multirow{2}{*}{79} \\
\hline Reverse & GCCCAATACGACCAAATCAGAG & \\
\hline \multicolumn{3}{|l|}{ Survivin-methylation } \\
\hline Methylated forward & GGCGGGAGGATTATAATTTTCG & \multirow{2}{*}{$164 b p$} \\
\hline Methylated reverse & CCGCСАССТСТАССАACG & \\
\hline \multicolumn{3}{|l|}{ Survivin-methylation } \\
\hline Unmethylated forward & GGTGGGAGGATTATAATTTTTG & \multirow{2}{*}{$168 b p$} \\
\hline Unmethylated reverse & АССАССАССАССТСТАССААСА & \\
\hline $\begin{array}{l}\text { GAPDH: Glyceraldehyde-3-1 } \\
\text { containing } 5 .\end{array}$ & dehydrogenase; BIRC5: Baculoviral in & poptosis repeat- \\
\hline
\end{tabular}

Ficoll method using a density-gradient centrifuge (Lymphodex, Inno-Train, Kronberg, Germany) and were directed to a $-70^{\circ} \mathrm{C}$ refrigerator until next step. Total ribonucleic acid (RNA) was extracted from PBMCs by RNA isolation kit (BioFACTTM Total RNA Prep Kit, Daejeon, South Korea) according to the manufacturer's instructions. DNA isolation from PBMCs was performed using Blood Genomic DNA extraction mini kit (Favorgen Biotech, Corp., Ping-Tung, Taiwan). DNA integrity was checked by $2 \%$ agarose electrophoresis.
The methylation levels of BIRC5 gene were assessed by methylation-specific PCR (MS-PCR) technique according to the manufacturer's instructions. The bisulfite modification was performed by EZ DNA Methylation-GoldTM Kit (Zymo Research, Cat No. D5006, The Epigenetics Company, Irvine, CA, USA). The primer sequences for unmethylated promoter sequences were previously designed. ${ }^{29}$ The expression levels of methylated and unmethylated survivin were measured by real time quantitative PCR

Table 2. Demographic, clinical, and laboratory characteristics of participants

\begin{tabular}{|c|c|c|c|c|c|c|c|c|c|c|c|}
\hline & \multicolumn{5}{|c|}{ BD group $(n=43)$} & \multicolumn{5}{|c|}{ Control group $(n=44)$} & \multirow[b]{2}{*}{$p$} \\
\hline & $\mathrm{n}$ & $\%$ & Mean \pm SD & Median & IQR & $\mathrm{n}$ & $\%$ & Mean \pm SD & Median & IQR & \\
\hline Age (year) & & & $36.6 \pm 10.1$ & & & & & $35.4 \pm 7.5$ & & & 0.234 \\
\hline $\begin{array}{l}\text { Sex } \\
\quad \text { Male } \\
\text { Female }\end{array}$ & $\begin{array}{l}22 \\
21\end{array}$ & $\begin{array}{l}51.2 \\
48.8\end{array}$ & & & & $\begin{array}{l}23 \\
21\end{array}$ & $\begin{array}{l}52.3 \\
47.7\end{array}$ & & & & 0.508 \\
\hline Disease duration before diagnosis (month) & & & & 37 & 21 & & & & - & - & \\
\hline Oral aphthous ulcer & 40 & 93.0 & & & & & & & & & \\
\hline Genital ulcer & 29 & 67.4 & & & & & & & & & \\
\hline Positive pathergy & 23 & 53.5 & & & & & & & & & \\
\hline Arthritis & 21 & 48.8 & & & & & & & & & \\
\hline Erythema nodosum & 18 & 41.8 & & & & & & & & & \\
\hline Uveitis & 15 & 34.9 & & & & & & & & & \\
\hline Pseudofolliculitis & 6 & 14.0 & & & & & & & & & \\
\hline CNS involvement & 4 & 9.3 & & & & & & & & & \\
\hline HLA-B5 & 23 & 53.5 & & & & & & & & & \\
\hline HLA-B51 & 22 & 51.2 & & & & & & & & & \\
\hline
\end{tabular}


Table 3. Plasma survivin levels in patients with various demographic and clinical manifestations of Behçet's disease

\begin{tabular}{|c|c|c|c|c|}
\hline & \multicolumn{2}{|c|}{ Frequency } & \multirow{2}{*}{$\begin{array}{c}\begin{array}{c}\text { Plasma survivin } \\
\text { levels }\end{array} \\
\text { Mean } \pm \mathrm{SD}\end{array}$} & \multirow[b]{2}{*}{$p$} \\
\hline & $\mathrm{n}$ & $\%$ & & \\
\hline \multicolumn{5}{|l|}{ Sex } \\
\hline Male & 22 & 51.2 & $96.2 \pm 25.7$ & \multirow{2}{*}{0.855} \\
\hline Female & 21 & 48.8 & $102.0 \pm 24.1$ & \\
\hline \multicolumn{5}{|c|}{ Genital ulcer } \\
\hline Yes & 29 & 67.4 & $98.6 \pm 22.9$ & \multirow{2}{*}{0.993} \\
\hline No & 14 & 32.6 & $98.7 \pm 26.8$ & \\
\hline \multicolumn{5}{|l|}{ Uveitis } \\
\hline Yes & 15 & 76.1 & $94.9 \pm 23.5$ & \multirow{2}{*}{0.666} \\
\hline No & 28 & 23.9 & $99.8 \pm 26.1$ & \\
\hline \multicolumn{5}{|c|}{ Positive pathergy } \\
\hline Yes & 23 & 53.5 & $97.7 \pm 26.3$ & \multirow{2}{*}{0.855} \\
\hline No & 20 & 46.5 & $99.9 \pm 24.3$ & \\
\hline \multicolumn{5}{|c|}{ Skin lesions } \\
\hline Yes & 18 & 41.9 & $95.8 \pm 25.9$ & \multirow{2}{*}{0.619} \\
\hline No & 25 & 58.1 & $101.6 \pm 25.3$ & \\
\hline \multicolumn{5}{|l|}{ Arthritis } \\
\hline Yes & 21 & 48.8 & $100.7 \pm 32.1$ & \multirow{2}{*}{0.490} \\
\hline No & 22 & 51.2 & $97.3 \pm 24.5$ & \\
\hline
\end{tabular}

LightCycler 96 instrument (Roche Diagnostics $\mathrm{GmbH}$, Mannheim, Germany, and made in Switzerland) according to the manufacturer's instructions. The specific primers and PCR program are indicated in Table 1 . We used glyceraldehyde-3-phosphate dehydrogenase as reference gene. All experiments were triplicated.

Plasma levels of survivin were measured by Human survivin ZellBio $\mathrm{GmbH}$ enzyme-linked immunosorbent assay (ELISA) kit (Cat. No: ZB-13904C-H9648, Ulm, Germany) according to the manufacturer's instructions. We expressed results as picogram of survivin per milliliter plasma $(\mathrm{pg} / \mathrm{mL})$.

\section{Statistical analysis}

Statistical analysis was performed using the SPSS version 16.0 (SPSS Inc., Chicago, IL, USA) and GraphPad Prism version 7.03 software (GraphPad, San Diego, USA). We reported continuous variables as means \pm standard deviation and categorical variables as frequency and percentage. We compared categorical variables in studied groups by chi-squared test. Independent samples t-test or Mann-Whitney $\mathrm{U}$ test as appropriate was used for comparing continuous variables. $P$ value less than 0.05 was considered as statistically significant.

\section{RESULTS}

There were no significant differences in sex and age between $\mathrm{BD}$ and control groups. The demographic and clinical characteristics of participants are shown in Table 2. Oral aphthous ulcer, genital ulcer, and skin lesions were the most common clinical manifestations of BD patients.

The methylation status of BIRC5 gene in PBMCs of BD and control groups was assessed using MS-PCR. Real-time PCR showed that the DNA samples of BD and control groups were not different in methylated and unmethylated areas and alleles were heterozygote (Figure 1).

We measured the plasma levels of survivin in BD and control groups with ELISA. No significant difference was observed in plasma levels of survivin in BD $(98.86 \pm 25.5 \mathrm{pg} / \mathrm{mL})$ and control $(118.16 \pm 37.4 \mathrm{pg} / \mathrm{mL})$ groups (Figure 2). In addition, differences in plasma survivin levels in patients with various demographic and clinical manifestations of $\mathrm{BD}$ were not significant (Table 3). There was no significant correlation between survivin plasma levels and BD activity assessed by BDCAF ( $r=0.117$, $\mathrm{p}=0.569)$, IBDDAM $(\mathrm{r}=-0.132, \mathrm{p}=0.552)$, and TIAI ( $\mathrm{r}=0.361, \mathrm{p}=0.191)$ (Table 4).

Table 4. Correlation between survivin plasma levels and Behçet's disease activity

\begin{tabular}{|c|c|c|c|c|c|c|}
\hline & \multicolumn{2}{|l|}{ BDCAF } & \multicolumn{2}{|l|}{ IBDDAM } & \multicolumn{2}{|l|}{ TIAI } \\
\hline & Pearson correlation & $p$ & Pearson correlation & $p$ & Pearson correlation & $p$ \\
\hline Plasma survivin $(\mathrm{pg} / \mathrm{mL})$ & 0.117 & 0.569 & -0.132 & 0.522 & 0.361 & 0.191 \\
\hline
\end{tabular}




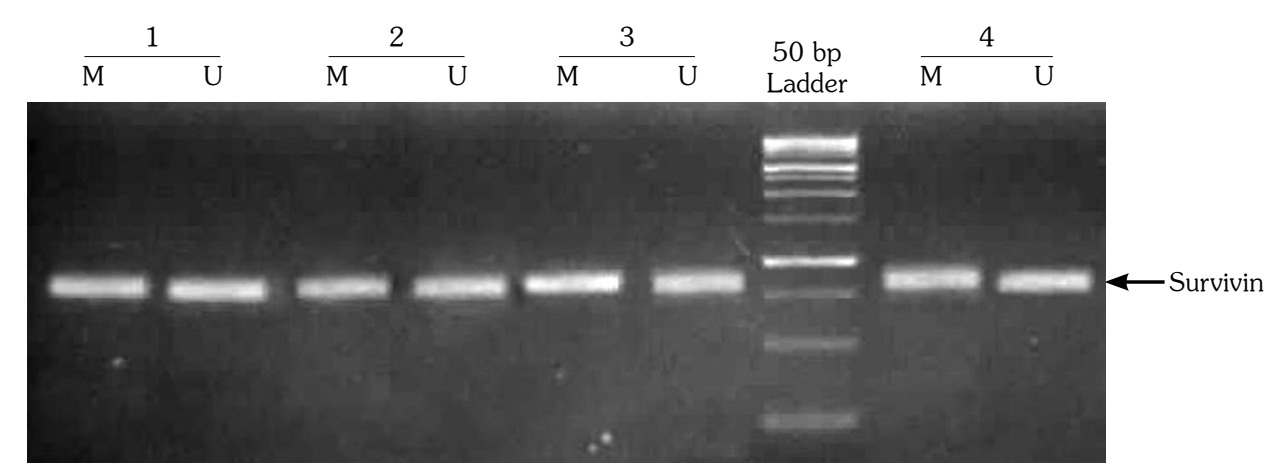

Figure 1. Methylation-specific polymerase chain reaction product analysis of blood baculoviral inhibitor of apoptosis repeat-containing 5 genes by agarose gel electrophoresis and ethidium bromide staining. Lanes 3-4: normal blood samples, lanes 1-2: Behçet's disease patients' blood samples. Each sample was represented by two successive lanes, one for methylated (M) band and another for unmethylated $(\mathrm{U})$ band.

\section{DISCUSSION}

Activated auto-reactive lymphocytes play an essential role in the pathogenesis of $\mathrm{BD}$. Failure to remove activated lymphocytes can result in augmented inflammatory reaction. ${ }^{30}$ Apoptosis is one the mechanisms that control inflammatory response by removing activated cells. Several studies considered the role of apoptosis in the pathogenesis of $\mathrm{BD}$. Hamzaoui et al., ${ }^{10}$ in a study on $50 \mathrm{BD}$ patients reported a high serum soluble Fas/APO (sFas/APO-1) level in active $\mathrm{BD}$ compared with healthy controls. sFas/APO-1 is a soluble receptor which, by binding to Fas ligand (FasL), prevents this ligand's interaction with Fas. This process leads to the down-regulation of apoptosis. Hamzaoui et al., 9 in another study assessed B-cell lymphoma 2 (BcL-2) expression in the lymphocytes obtained from body fluids including blood, cerebrospinal fluid, and bronchoalveolar lavage of patients with $\mathrm{BD}$. They found higher levels of $\mathrm{Bcl}-2$ expression in the lymphocytes of $\mathrm{BD}$ patients compared with the controls. Yang et al. ${ }^{13}$ found resistance to Fas-mediated apoptosis in the PBMCs of patients with BD. They induced apoptosis in the PBMCs by using anti-Fas antibody and noted lesser apoptosis in the PBMCs of patients with BD (19.7\%) compared with controls (26.1\%). Interestingly, in another study, they showed higher Fas expression on the $\mathrm{T}$ cells of $\mathrm{BD}$ patients. ${ }^{14}$ Todaro et al. ${ }^{31}$ reported resistance to spontaneous and cluster (a)

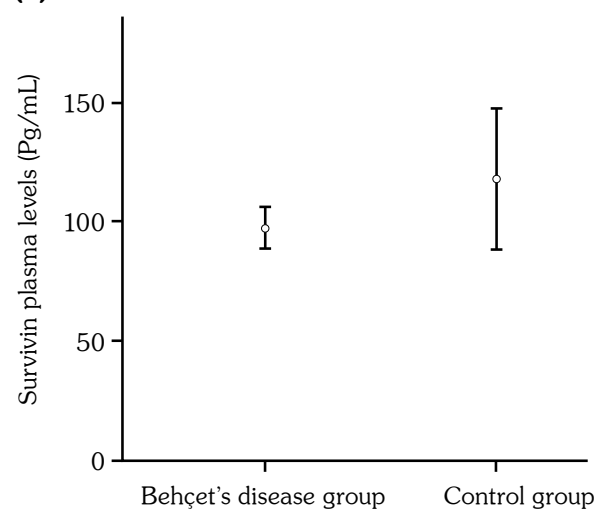

(b)

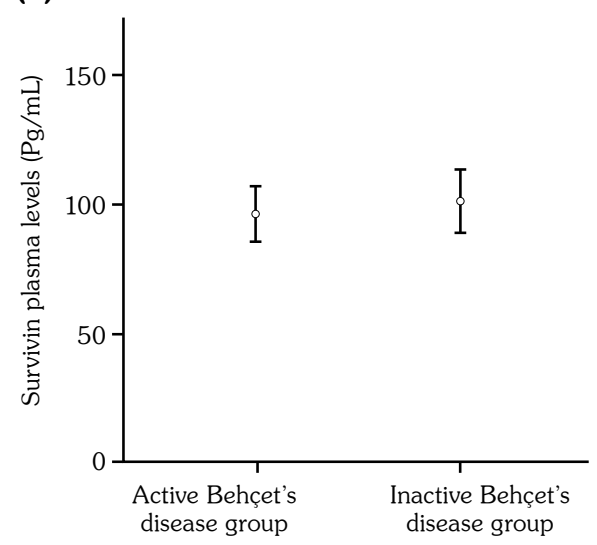

Figure 2. Survivin plasma levels in studied groups: (a) Behçet's disease group compared with control group, (b) active Behçet's disease group compared with inactive Behçet's disease group. 
of differentiation (CD) 95-induced apoptosis in $\mathrm{T}$ cells of patients with $\mathrm{BD}$. They found that a higher expression of nuclear factor- $\kappa \beta$ in lymphocytes leads to a higher expression of cellular FLICE [FADD-like interleukin (IL)-1 beta-converting enzyme]-inhibitory protein and Bcl-extra large, and resistance to apoptosis. ${ }^{31}$ Baris et al. ${ }^{12}$ performed immunohistochemical staining for $\mathrm{Bcl}-2$ and Fas in biopsies from skin lesions from 29 patients with BD and 10 patients with non-specific chronic inflammatory skin lesions. They found staining for $\mathrm{Bcl}-2$ in $76 \%$ of cutaneous lesions lymphocytes in $\mathrm{BD}$ patients and in $20 \%$ of controls. Fas staining was not detected in cutaneous lesions lymphocytes of BD group. ${ }^{12}$ However, lymphocytes in 33\% of biopsies of control group stained for Fas. IL-12 by suppression of CD95-induced cell death causes resistance to activation-induced cell death in $\mathrm{T}$ cells of patients with BD and proliferation of auto-reactive $\mathrm{T}$ helper type I cells and prolong inflammatory attack. ${ }^{12}$

Survivin with expression in the nucleus, cytoplasm, and mitochondria of proliferating cells, like activated T cells, exert several regulatory functions including: (i) aiding cell division by forming a chromosomal passenger complex after attaching to borealin, inner centromere protein, and Aurora in the $\mathrm{G} 2 / \mathrm{M}$ phase of mitosis, (ii) suppression of apoptosis by forming a complex with X-linked IAPs and inhibiting caspase-3 in the cytoplasm. It also prevents the activation of caspase- 9 by inhibiting the release of the second mitochondria derived activator of caspases (Smac/Diablo). 7,8 Despite many studies about FasL/Fas-mediated apoptosis dysregulations in patients with $\mathrm{BD}$, limited data exist about survivin-mediated apoptosis dysregulation in BD. In the present study, there were no significant differences in the methylation of the BIRC5 gene and plasma survivin levels in patients with $\mathrm{BD}$ compared with healthy controls.

This study has some limitations. With this study, we cannot rule out the role of survivin in the apoptosis dysregulation in $\mathrm{BD}$. At first, a relatively small number of patients may have led to type II error. In addition, alteration in posttranslational modifications of survivin including phosphorylation and acetylation that play a key role in regulating survivin function may have been involved.
In conclusion, our study did not show any evidence of association between alteration in the BIRC5 gene methylation, survivin production, and apoptosis dysregulation in BD patients.

\section{Acknowledgements}

We would like to express our thanks to Leila Khabbazi for editing the text as well as the patients who participated in the study.

\section{Declaration of conflicting interests}

The authors declared no conflicts of interest with respect to the authorship and/or publication of this article.

\section{Funding}

The authors received no financial support for the research and/or authorship of this article.

\section{REFERENCES}

1. Tong B, Liu X, Xiao J, Su G. Immunopathogenesis of Behcet's Disease. Front Immunol 2019;10:665.

2. Khabbazi A, Rashtchizadeh N, Ghorbanihaghjo A, Hajialiloo M, Ghojazadeh M, Taei R, et al. The status of serum vitamin $\mathrm{D}$ in patients with active Behcet's disease compared with controls. Int $J$ Rheum Dis 2014;17:430-4.

3. Malek Mahdavi A, Khabbazi A, Yaaghoobian B, Ghojazadeh M, Agamohammadi R, Kheyrollahiyan A, et al. Cigarette smoking and risk of Behcet's disease: a propensity score matching analysis. Mod Rheumatol 2019;29:633-9.

4. Meguro A, Inoko H, Ota M, Katsuyama Y, Oka A, Okada E, et al. Genetics of Behçet disease inside and outside the MHC. Ann Rheum Dis. 2010;69:747-54.

5. Dehghanzadeh R, Babaloo Z, Sakhinia E, Khabazi A, Shanehbandi D, Sadigh-Eteghad S, et al. IL-27 Gene Polymorphisms in Iranian Patients with Behcet's Disease. Clin Lab 2016;62:855-61.

6. Hosseini A, Shanehbandi D, Estiar MA, Gholizadeh S, Khabbazi A, Khodadadi $\mathrm{H}$, et al. A Single Nucleotide Polymorphism in the FOXP3 Gene Associated with Behçet's Disease in an Iranian Population. Clin Lab 2015;61:1897-903.

7. Gravina G, Wasén C, Garcia-Bonete MJ, Turkkila $M$, Erlandsson MC, Töyrä Silfverswärd S, et al. Survivin in autoimmune diseases. Autoimmun Rev 2017;16:845-55.

8. Pahlavan Y, Kahroba H, Samadi N, Karimi A, Ansarin K, Khabbazi A. Survivin modulatory role in autoimmune and autoinflammatory diseases. J Cell Physiol 2019;234:19440-50.

9. Hamzaoui K, Hamzaoui A, Zakraoui L, Chabbou A. Expression of Bcl-2 in inflammatory sites from 
patients with active Behçet's disease. Mediators Inflamm 1999;8:101-6.

10. Hamzaoui K, Hamzaoui A, Zakraoui L, Chabbou A. Levels of soluble Fas/APO-1 in patients with Behçet's disease. Mediators Inflamm 1998;7:111-4.

11. Wakisaka S, Takeba Y, Mihara S, Takeno M, Yamamoto S, Sakane T, et al. Aberrant Fas ligand expression in lymphocytes in patients with Behçet's disease. Int Arch Allergy Immunol 2002;129:175-80.

12. Baris YS, Yildiz L, Sentürk N, Kandemir B. Fas (CD95) and bcl-2 expression in active skin lesions of Behçet's disease. J Eur Acad Dermatol Venereol 2005;19:569-72.

13. Yang $\mathrm{P}$, Chen $\mathrm{L}$, Zhou $\mathrm{H}$, Zhong $\mathrm{H}$, Wang $\mathrm{H}$, Huang $\mathrm{X}$, et al. Resistance of lymphocytes to Fasmediated apoptosis in Behçet's disease and VogtKoyangi-Harada syndrome. Ocul Immunol Inflamm 2002;10:47-52.

14. Yang $P$, Ji L, Zhou H, Huang X, Xie C, Jin H, et al. Disturbed expression of Fas/FasL on CD4(+) and CD8(+)T cells in Behcet's disease, Vogt-KoyanagiHarada syndrome, and idiopathic anterior uveitis. Ocul Immunol Inflamm 2001;9:185-91.

15. Koike Y, Muroi E, Yoshizaki A, Ogawa F, Yanaba $\mathrm{K}$, Takenaka $\mathrm{M}$, et al. Autoantibody against survivin in patients with systemic sclerosis. $\mathrm{J}$ Rheumatol 2010;37:1864-70.

16. Ahn JK, Oh JM, Lee J, Bae EK, Ahn KS, Cha HS, et al. Increased extracellular survivin in the synovial fluid of rheumatoid arthritis patients: fibroblast-like synoviocytes as a potential source of extracellular survivin. Inflammation 2010;33:381-8.

17. Isgren A, Forslind K, Erlandsson M, Axelsson C, Andersson S, Lund A, et al. High survivin levels predict poor clinical response to infliximab treatment in patients with rheumatoid arthritis. Semin Arthritis Rheum 2012;41:652-7.

18. Chun-Lai T, Murad S, Erlandsson MC, Hussein $\mathrm{H}$, Sulaiman W, Dhaliwal JS, et al. Recognizing rheumatoid arthritis: oncoprotein survivin opens new possibilities: a population-based case-control study. Medicine (Baltimore) 2015;94:e468.

19. Pahlavan Y, Samadi N, Ansarin K, Khabbazi A. Phosphorylation Modulates Survivin Function in Behcet's Disease. Adv Pharm Bull 2020;10:278-83.

20. Alipour S, Nouri M, Sakhinia E, Samadi N, Roshanravan N, Ghavami A, et al. Epigenetic alterations in chronic disease focusing on Behçet's disease: Review. Biomed Pharmacother 2017;91:526-33.

21. Shirvani SS, Nouri M, Sakhinia E, Babaloo Z, Jadideslam G, Shahriar A, et al. The expression and methylation status of vitamin $D$ receptor gene in Behcet's disease. Immun Inflamm Dis 2019;7:308-17.

22. Alipour S, Sakhinia E, Khabbazi A, Samadi N, Babaloo Z, Azad M, et al. Methylation status of interleukin- 6 gene promoter in patients with Behçet's disease. Reumatol Clin 2020;16:229-34.

23. Alipour S, Nouri M, Khabbazi A, Samadi N, Babaloo Z, Abolhasani S, et al. Hypermethylation of IL-10 gene is responsible for its low mRNA expression in Behçet's disease. J Cell Biochem 2018;119:6614-22.

24. Abdi A, Khabazi A, Sakhinia E, Alipour S, Talei M, Babaloo Z. Evaluation of SOCS1 methylation in patients with Behcet's disease. Immunol Lett 2018;203:15-20.

25. International Team for the Revision of the International Criteria for Behçet's Disease (ITR-ICBD). The International Criteria for Behçet's Disease (ICBD): a collaborative study of 27 countries on the sensitivity and specificity of the new criteria. $\mathrm{J}$ Eur Acad Dermatol Venereol 2014;28:338-47.

26. Davatchi F. Iran Behcet's disease dynamic activity measure. Abstracts of the XIIth European Congress of Rheumatology. Hungarian Rheumatol 1991;32:134.

27. Lawton G, Bhakta BB, Chamberlain MA, Tennant A. The Behcet's disease activity index. Rheumatology (Oxford) 2004;43:73-8.

28. Shahram F, Khabbazi A, Nadji A, Ziaie N, Banihashemi AT, Davatchi F. Comparison of existing disease activity indices in the follow-up of patients with Behçet's disease. Mod Rheumatol 2009;19:536-41.

29. Guo L, Huang C, Ji QJ. Aberrant promoter hypermethylation of p16, survivin, and retinoblastoma in gastric cancer. Bratisl Lek Listy 2017;118:164-8.

30. Thompson CB. Apoptosis in the pathogenesis and treatment of disease. Science 1995;267:1456-62.

31. Todaro M, Zerilli M, Triolo G, Iovino F, Patti M, Accardo-Palumbo A, et al. NF-kappaB protects Behçet's disease $T$ cells against CD95-induced apoptosis up-regulating antiapoptotic proteins. Arthritis Rheum 2005;52:2179-91. 